$25^{\text {th }}$ October 2017: This paper is not the copy of record and may not exactly replicate the authoritative document published in the journal. The final article will be available from the journal website: Golding, K., Fife-Schaw, C. \& Kneebone, I. I. (in press). A pilot randomised controlled trial of self-help relaxation to reduce poststroke depression. Clinical Rehabilitation.

A pilot randomised controlled trial of self-help relaxation to reduce post-stroke depression

Katherine Golding ${ }^{1}$, Chris Fife-Schaw ${ }^{2}$, and Ian Kneebone ${ }^{3}$

${ }^{1}$ Psychology Department, St George's University Hospitals NHS Foundation Trust, UK

${ }^{2}$ School of Psychology, University of Surrey, UK

${ }^{3}$ Discipline of Clinical Psychology, Graduate School of Health, University of

Technology Sydney, Australia

Corresponding author:

Dr Katherine Golding Psychology Department,

St George's University Hospitals NHS Foundation Trust

Blackshaw Road

Tooting

London SW17 0QT

E kate.golding@stgeorges.nhs.uk 
Abstract

Objective: To consider the potential of self-help relaxation training to treat depression after stroke.

Design: Randomised controlled trial with cross-over at 3 months.

Setting: Community.

Participants: Twenty-one people with stroke, aged 49 to 82 years.

Intervention: Autogenic relaxation CD.

Main measure: Hospital Anxiety and Depression Scale - Depression sub-scale (HADS-D).

Results: No difference in depression change scores was identified between the treatment and control groups, however on two follow ups significant positive differences relative to screening were found for the treatment group (at 2 months $Z=$ 2.55, $p=.011$ and 12 months $Z=-2.44, \mathrm{p}=.015)$. A partial $\eta^{2}=.07$ was identified. Conclusions: Self-help relaxation holds promise as a self-help treatment for depression after stroke. Findings from this trial, considered with others of relaxation for depression, suggests a study including a total of 80 participants would likely be sufficient to establish efficacy of the treatment, relative to controls, in those with stroke. 


\section{A pilot randomised controlled trial of self-help relaxation to reduce post-stroke}

\section{depression}

Depression is common after stroke, with a point prevalence rate of $31 \%,{ }^{1}$ and a cumulative incidence over 15 years of $55 \% .^{2}$ Aside from the distress of the condition itself, depression after stroke is associated with reduced functional ability and increased mortality. $^{3}$

The evidence for effective psychological interventions for established post-stroke depression is limited, ${ }^{4}$ although one recent study did find behavioural activation promising. ${ }^{5}$ However the treatment required one to one therapist contacts and on this basis is costly. An inexpensive alternative treatment may be relaxation training, which has been effective in a large number of studies. ${ }^{6}$

We recently conducted a study that demonstrated the potential effectiveness of relaxation to treat anxiety post-stroke via a self-help format. ${ }^{7,8}$ The use of relaxation CDs at home with minimal telephone support appeared feasible and acceptable to deliver, few participants dropped out and the intervention was of low cost. This is a secondary analysis of the data, focussed on recorded depressive symptoms, undertaken 
to provide information on effect size to allow a power calculation for a definitive treatment study.

\section{Methods}

Ethical approval was granted by the Faculty of Arts and Human Sciences at the University of Surrey, UK (Reference no: 759-PSY-12 RS).

The method of this study is described in detail elsewhere. ${ }^{7,8}$ Essentially respondents to an advert inviting stroke survivors experiencing anxiety to participate in the trial were screened. Screening was by telephone and included assessments of mood (Hospital Anxiety and Depression Scale ${ }^{9}$ ) and cognitive ability (Telephone Interview of Cognitive Status $\left.^{10}\right)$. Participation was determined on the basis of an above cut-off score for anxiety of $\geq 6$ on the Hospital Anxiety and Depression Scale - Anxiety subscale and a score $\geq 20$ on the Telephone Interview of Cognitive Status. The latter was to ensure participants did not have significant cognitive impairment.

The Hospital Anxiety and Depression Scale is a 14 item self-report scale divided into two 7 item subscales; anxiety and depression. For this study scores on the depression sub-scale were used. 
After screening participants were randomised to the intervention or control condition. The intervention group received a self-help autogenic relaxation CD. ${ }^{11}$ They were asked to practice the relaxation five times weekly for one month. They were provided with a diary to record the frequency of their practice. Control group participants received the $\mathrm{CD}$ and the same instructions three months later.

The autogenic relaxation CD asks participants to focus on their body and experience it in ways such as "heavy", "warm" or "refreshed". The script states for instance "Focus your passive attention on whichever of your arms is most active and repeat the following 'My arm is heavy. My entire arm and hand and fingers are very heavy and limp and relaxed","11.

All participants completed the Hospital Anxiety and Depression Scale immediately prior to the intervention group receiving the $\mathrm{CD}$ (pre-intervention), one month later (post-intervention) and at two month and three month follow-ups. Controls received the intervention after the three month follow-up of the intervention group. Final follow up for both groups was approximately one year after completing the intervention. All assessments were conducted by telephone by the same researcher. Two participants in the intervention arm and three in the control arm had incomplete data at follow-up and 
we conservativelty imputed their scores using their last observation carried forward (LOCF).

Mann-Whitney U independent samples tests were used to consider whether there were differences between the groups with respect to change in depression from baseline. Wilcoxon Signed Ranks Tests were conducted to identify any changes in depression scores from screening to follow-up. To estimate a likely effect size for future power calculations a mixed measures ANOVA comparing screening to follow-up at 3 months was conducted. Data analyses were carried out using SPSS Version 20.0.

\section{Results}

Figure 1 shows details of recruitment and follow-up. Baseline demographic data are in Table 1. Table 2 shows the scores on the depression subscale of the Hospital Anxiety and Depression Scale.

Figure 1 about here

Table 1 about here

Table 2 about here

Analysis of the change in depression scores failed to indicate any differences between the intervention and control groups, however the Wilcoxon Signed Ranks Test did identify significant positive changes between screening and follow-up at $2(Z=-2.55, p$ 
$=.011, \mathrm{r}=.57)$ and 12 months $(Z=-2.44, \mathrm{p}=.015, \mathrm{r}=.55)$ for the intervention group. The mixed measures ANOVA yielded a partial $\eta^{2}=.07$. This suggests a sufficiently powered study to identify an effect of relaxation training on depression would require a sample of 30 participants, 15 per study arm, to achieve a power of 0.8 at $\alpha=.05$.

\section{Discussion}

This pilot study provides preliminary information on which to base a full scale trial of self-help autogenic relaxation training for depression after stroke. While change in depression scores did not differ between intervention and controls this is hardly surprising given participants were selected on the basis of anxiety, not depression scores, meaning that the sample was not of those 'high' in depression, i.e., those having high potential for change. In addition, these findings are also likely due to considerable within-group variability.

The required sample size indicated by the size of change detected is low (15 participants per trial arm) considering the usual effect size (SMD -0.59, 95\% CI -0.94 to -0.24) from research on relaxation for depression ${ }^{6}$. A conservative estimate would be 37 participants per group in a two arm trial $(\alpha$ err prob $=0.05$, Power $(1-\beta$ err prob $)=0.8)$. On this basis a future study with 80 participants in total would more than comfortably have adequate power. 
It is important to emphasise that it is not only the depression change scores identified that forms the basis for reccomending a further study. The wider context is the sound evidence for utility in persons without stroke ${ }^{6}$ and in this same sample, that the use of CDs at home with minimal telephone support was acceptable to participants, had few drop outs and was established as relatively low cost. ${ }^{7}$

The major limitation of this pilot study is that participation was determined based on anxiety scores. It remains a question whether those with greater depression would be as likely to enrol in a self-help programme as those with anxiety. Certainly depression can be characterised by lack of motivation, although evidence from other self-help interventions for depression in non-stroke populations is positive. ${ }^{12}$

It is also important to recognise that the participants in this study had intact language ability and minimal cognitive deficits. Significant communication disorder and cognitive impairment is common after stroke. ${ }^{13}$ It is conceivable both these complications might interfere with a stroke survivors ability to take up a self-help intervention like relaxation training. 
An appropriately powered trial would allow definitive statements to be made about the usefulness of autogenic relaxation training in treating post-stroke depression in those without significant cognitve or communication disorder. Depending on findings from such a trial, investigating the usefulness of the intervention with the wider stroke population in terms of disability and location (e.g., ward-based versus community) may be indicated.

\section{Clinical Messages}

- An adequately powered trial of an autogenic, relaxation $\mathrm{CD}$ as treatment for symptomatie depression after stroke would need to recruit 80 patients in total.

\section{Conflict of Interest}

The authors declare that there is no conflict of interest.

\section{Funding}

This research received no specific grant from any funding agency in the public, commercial, or not-for-profit sectors. 


\section{References}

1. Hackett ML and Pickles K. Part I: Frequency of depression after stroke: an updated systematic review and meta-analysis of observational studies. Int $J$ Stroke 2014; 9: 1017-1025.

2. Ayerbe L, Ayis S, Crichton S, et al. The natural history of depression up to 15 years after stroke: the South London Stroke Register. Stroke 2013; 44: 1105-10.

3. Kutlubaev MA and Hackett ML. Part II: Predictors of depression after stroke and impact of depression on stroke outcome: an updated systematic review of observational studies. Int J Stroke 2014; 9: 1026-1036.

4. Hackett ML, Anderson CS, House A, et al. Interventions for treating depression after stroke. The Cochrane Database of Systematic Review 2008; ID: CD003437.

5. Thomas SA, Walker MF, Macniven JA, et al. Communication and Low Mood (CALM): a randomized controlled trial of behavioural therapy for stroke patients with aphasia. Clin Rehabil 2013; 27: 398-408.

6. Jorm AF, Morgan AJ and Hetrick SE. Relaxation for depression. The Cochrane Database of Systematic Reviews; ID: CD007142

7. Golding K, Kneebone I and Fife-Schaw C. Self-help relaxation for post-stroke anxiety: a randomised, controlled pilot study. Clin Rehabil, 2016; 30: 174-180. 
8. Golding K, Fife-Schaw C and Kneebone II. Twelve month follow-up on a randomised controlled trial of relaxation training for post-stroke anxiety. Clin Rehabil 2017; 31: 1164-1167.

9. Zigmond A and Snaith RP. The Hospital Anxiety and Depression Scale. Acta Psychiatrica Scandinavica 1983; 67(6): 361-370.

10. Brandt J, Spencer M and Folstein M. The Telephone Interview for Cognitive Status. Cogn Behav Neurol 1988; 1: 111-118.

11. Winkler R, James R, Fatovich B, et al. Migraine and tension headaches: a multi-modal approach to the prevention and control of headache pain. University of Western Australia: Self-Care Research Team;1982.

12. Cuijpers P, Donker T, Johansson R, et al. Self-guided psychological treatment for depressive symptoms: a meta-analysis. PLoS ONE 2011; 6: e21274.

13. Lincoln NB, Kneebone II, Macniven JA and Morris RC. Psychological Management of Stroke. Chichester, UK: John Wiley \& Sons; 2012. 
Figure 1. Flow diagram showing the procedure of allocation, follow up and analysis. ${ }^{8}$

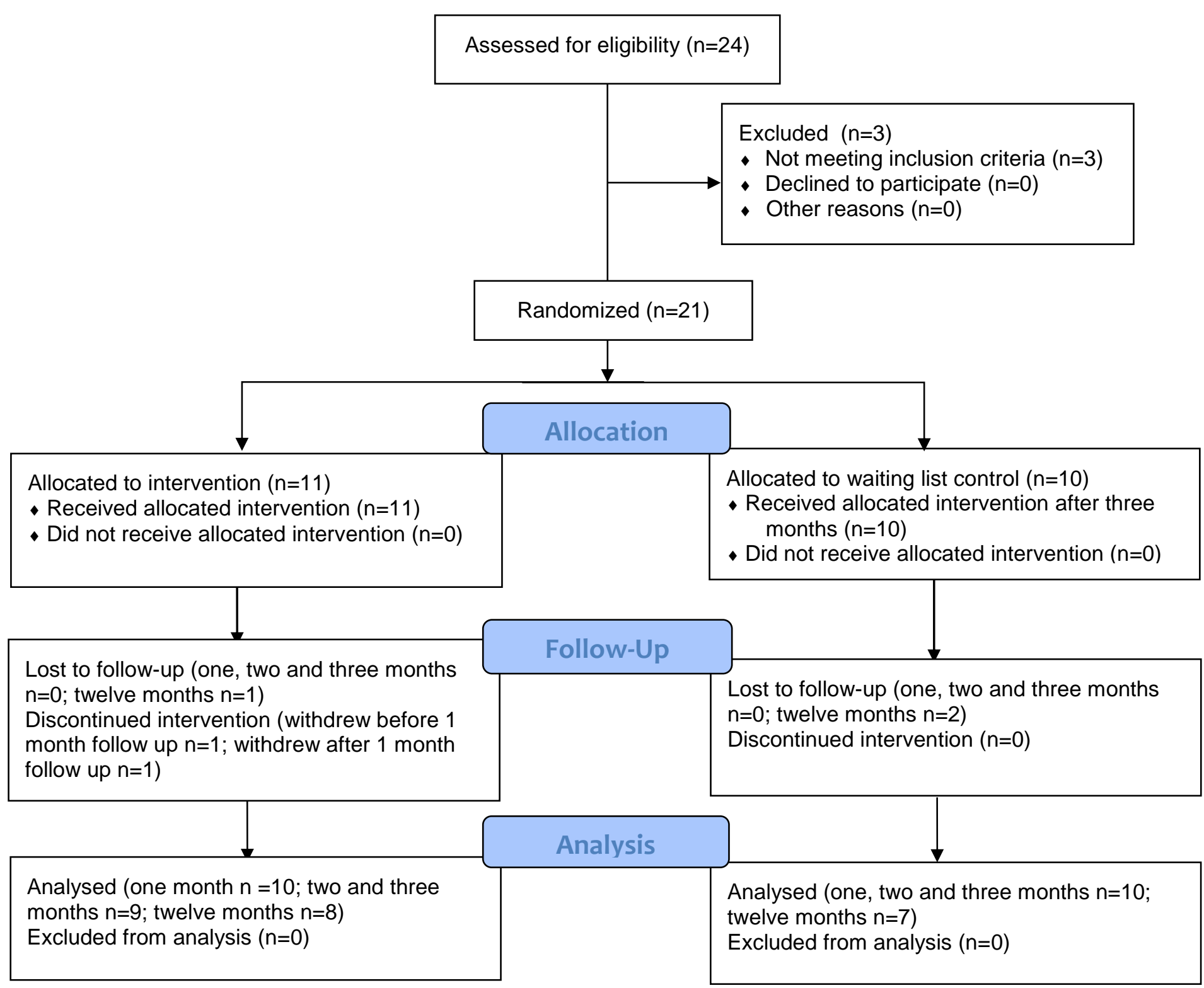




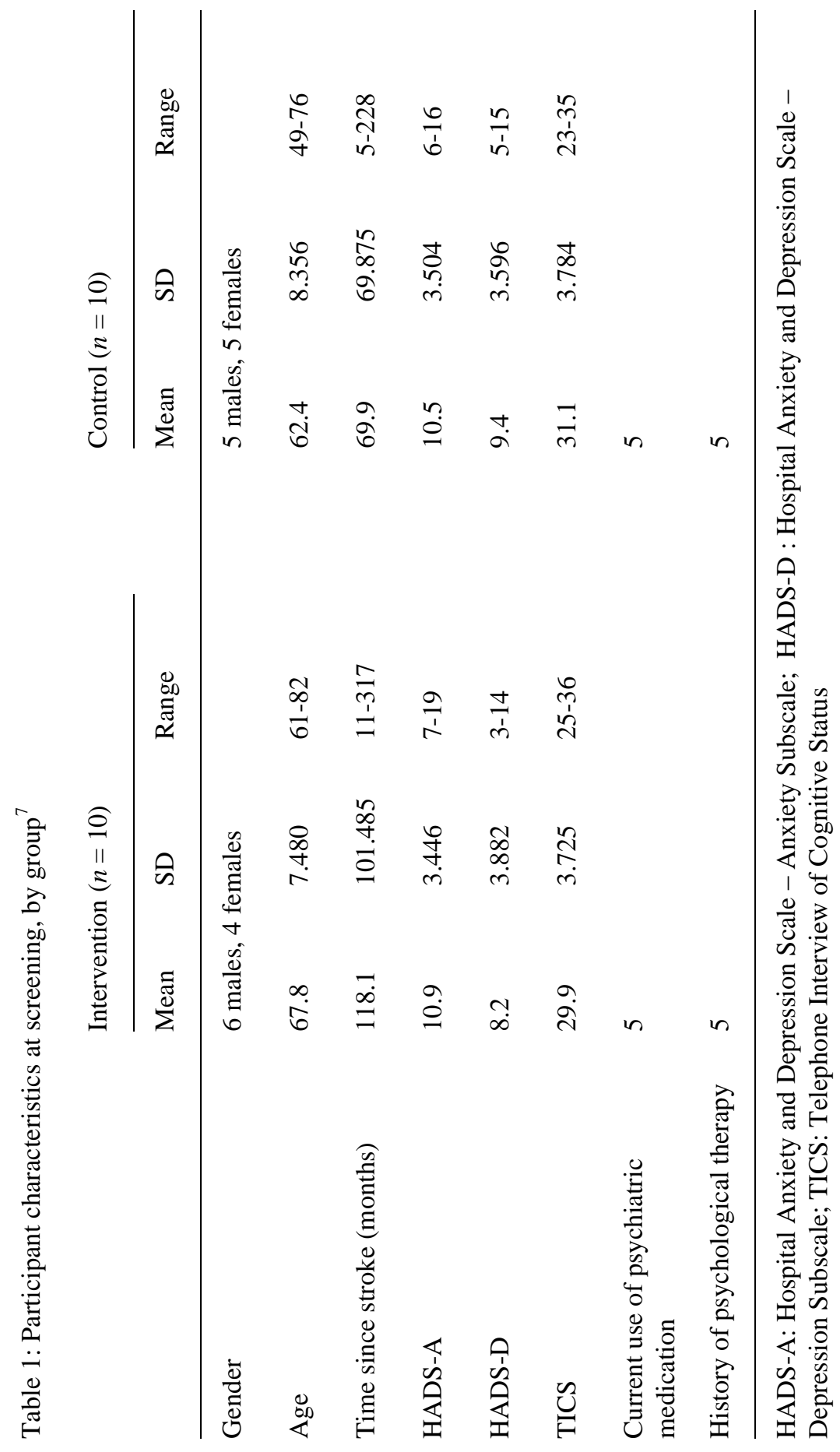


Table 2: Hospital Anxiety and Depression Scale - Depression sub-scale scores at preintervention, post-intervention (one month) and follow-up by group.

\begin{tabular}{|c|c|c|c|c|c|c|c|c|c|c|}
\hline & \multicolumn{5}{|c|}{ Intervention $(n=10)$} & \multicolumn{5}{|c|}{ Waiting list control $(n=10)$} \\
\hline & Mean & $\mathrm{SD}$ & Median & Range & Caseness & Mean & $\mathrm{SD}$ & Median & Range & Caseness \\
\hline Pre-intervention & 8.20 & 3.88 & 7.5 & 3-14 & 5 & 9.40 & 3.60 & 9 & $5-15$ & 5 \\
\hline $\begin{array}{l}1 \text { Month post- } \\
\text { intervention }\end{array}$ & 6.10 & 3.67 & 5.5 & $1-13$ & 2 & 9.20 & 4.71 & 7.5 & $5-21$ & 3 \\
\hline $\begin{array}{l}2 \text { Months post- } \\
\text { intervention }\end{array}$ & 5.70 & 3.86 & 5.5 & $0-12$ & 3 & 8.80 & 4.05 & 7.5 & $5-19$ & 4 \\
\hline $\begin{array}{l}3 \text { Months post- } \\
\text { intervention }\end{array}$ & 5.80 & 3.99 & 4 & $1-13$ & 3 & 9.00 & 4.24 & 7 & $5-19$ & 3 \\
\hline $\begin{array}{l}12 \text { months } \\
\text { follow up }-* \text { all } \\
\text { treated }\end{array}$ & 5.50 & 4.28 & 5.5 & $1-14$ & 2 & 8.40 & 5.08 & 7.5 & $3-21$ & 3 \\
\hline
\end{tabular}

Note $:$ Caseness $=$ Clinical levels of depression, HADS-D score $\geq 9$ 